\title{
Growth and survival of the superorganism: ant colony macronutrient intake and investment
}

\author{
Yeisson Gutiérrez ${ }^{1}$, Tung Phung ${ }^{2}$, Harald Mumma², Arden Ambrose-Winters², Christoph \\ Scherber $^{3}$, and Chris Smith ${ }^{2}$ \\ ${ }^{1}$ University of Münster \\ ${ }^{2}$ Earlham College \\ ${ }^{3}$ Westfälische Wilhelms-Universität Münster
}

May 5, 2020

\begin{abstract}
In this study, we used two common ant species (Lasius niger and L. neoniger) to assay how they translate variation in the diet (both in composition and frequency) into growth. We measured colony development for over 8 months and measured several phenotypic traits of the worker caste, and examined whether forager preference corresponded with diet quality. Individuals (workers) and colonies (superorganisms) increased in size with increasing amounts of protein in the diet, and as a function of how much food was available. Optimal colony growth was a balance between survival and growth, and each of these were maximized with different nutrient regimes. Interestingly, forager preference was not totally aligned with the diet that maximized colony growth. Our results highlight that: 1) organism and superorganism size are controlled by the same nutrients, and this may reflect a common molecular basis for size across life's organizational levels, 2) there are nutrient trade-offs that are associated with life-history trade-offs, likely leading to selection for a balanced diet, and 3) the connection between the preference of foragers for different nutrients and how nutrient combinations affect colony success and demographics are complex and only beginning to be understood.
\end{abstract}

\section{INTRODUCTION}

Nutrition is an upstream organizer of most organismal processes, and thus dealing with variation in the availability of nutrients is among the most consequential challenges, and selective agents, faced by all organisms (Stearns, 1992; Zera \& Harshman, 2001). While many nutrients are necessary for maintenance and growth, the majority consumed and used are macronutrients ingested in high quantity, such as proteins, carbohydrates, and fats (Raubenheimer, Simpson, \& Mayntz, 2009). The molecular mechanisms that translate incoming macronutrients into maintenance, new tissue, or storage, are well understood, and tend to be highly conserved (Conlon \& Raff, 1999).

Superorganisms, like eusocial insects, are groups of individuals of the same species operating in a synergistic way (D. S. Wilson \& Sober, 1989). Superorganisms are characterized by the reproductive division of labour, such that some individuals do not reproduce (somatic - germ line division) (Hölldobler \& Wilson, 2009). The nutritional challenges of any cell or organism are also faced by superorganisms, but are compounded by the additional level of complexity (cooperating organisms on top of cooperating cells, etc.) - the labour that is divided amongst cells in 'unitary' organisms is divided amongst individuals in the superorganism. How, then, do nutritional challenges scale from organism to superorganism? Do organism and superorganism have different nutritional optima and/or face the same nutrition-mediated trade-offs? If individual and 
superorganism optima are not aligned, then processes occurring at the individual level may limit those at the superorganismal level.

Social insect colonies undergo a coordinated development that is responsive to the environment and also lineage/species specific, termed 'sociogenesis' (E. O. Wilson, 1985). 'Sociometry' is a general term applied to the metrics associated with superorganisms, such as colony size, individual size (and size distributions), the numbers and ratios of different castes, among others. As a general pattern in studies of sociometry and sociogenesis, worker size increases with the number of workers in the colony (Smith \& Tschinkel, 2006; Tschinkel, 1987, 1993, 1998). This relationship is at least in part due to increasing resource availability to developing individuals in larger colonies - increased nutrient availability does increase worker production and worker size (Goetsch, 1937; Metzl, Wheeler, \& Abouheif, 2018; Passera, 1974; Smith, 2007; Wills et al., 2015). Increased protein/nitrogen content has also been associated with the production of larger workers (majors/soldiers) and sexual castes (Bono \& Heithaus, 2002; Goetsch, 1937; Hunt \& Nalepa, 1994; Passera, 1974; Schmidt, Hunt, \& Smith, 2012; Smith, Anderson, Tillberg, Gadau, \& Suarez, 2008; Smith \& Suarez, 2010; Smith, 1942). However, previous studies have been largely observational or used natural foods (e.g., increased insect prey) that confound protein/nitrogen content with many other nutrient differences. Furthermore, many previous studies focus on short-term colony dynamics, documenting adult worker survival rather than longer-term growth (e.g., Dussutour \& Simpson, 2009, 2012; Wills et al., 2015).

The nutritional basis of individual and superorganism size is a major unresolved issue in the understanding of social insect growth and development. In the present study, we used ants as a model superorganism and employed a nutritional geometry framework (Simpson \& Raubenheimer, 1995) that allowed for the manipulation of both the ratio and amounts of protein and carbohydrate available to colonies. We hypothesized that worker size and colony size would both increase with increasing availability of protein in the diet - that is, worker number and size are both protein-limited. This hypothesis is consistent with sociometric observations. An important alternative hypothesis is that worker and colony development are limited by different nutrients (i.e., worker and colony optima differ). For example, worker size may indeed be protein-limited, but colonies may be more carbohydrate limited due to the metabolic demands of the standing crop of adult workers. This alternative hypothesis is premised on there being a nutritionally mediated life-history trade-off between growth (new tissue) and maintenance (current tissue, Fig. 1).

A division of labour inherent in social insect colonies is between growing individuals (larvae) and those that maintain the colony (workers). To further explore possible trade-offs between growth and maintenance, we examined the flow of nutrients through these two types of individual, larva and worker, using a stable isotope tracer experiment. We hypothesized that protein would be more rapidly and completely transferred to larvae while carbohydrates would persist longer in workers.

Lastly, we examined natural (field) colony preference for macronutrient ratios to test whether preference matched the nutrient ratios that maximized growth in the lab. We hypothesized that colonies would prefer what maximized lab growth. However, an alternative hypothesis is that worker preference is not aligned with colony growth (under lab conditions), but instead is more tuned to the adult worker optimum of high carbohydrates - this may be selectively advantageous by favouring colony maintenance over growth. Furthermore, workers are the collectors of the food and preferences based on their own physiology and current state build from the ancestral condition of solitary insects. Other alternative hypotheses include that colonies respond based on experience or environmental variation, among other factors.

\section{MATERIALS AND METHODS}

\section{Study species}

The experimental procedure was carried out simultaneously for two ant species: Lasius niger (L., 1758) (Fig. 1) commonly termed as the black garden ant, widespread in Europe and northern America (Klotz, 2008); 
and Lasius neoniger Emery, 1893 known as the turfgrass ant, distributed in northern and Midwestern North America (E. O. Wilson, 1955). Both species are highly abundant in urban/suburban lawns and gardens and have similar diets. Natural diets are hemipteran honeydew and living and dead insects (Klotz, 2008; E. O. Wilson, 1955).

L. niger (Fig. 2) queens were collected in Münster (NRW, Germany) during a single nuptial flight on July 5, 2017. L. neonigerqueens were collected in Richmond (IN, U.S.A) during two nuptial flights on June 30 and July 12, 2017. Queens were housed in 18x150 mm test tubes half-filled with water and plugged with cotton. Most females initiated egg-laying after the first week. No food was provided until the emergence of the first workers' cohort. Once workers were present, colonies were housed in $500 \mathrm{ml}$ plastic boxes containing cottonstoppered test tubes with water. Box walls were covered with fluon (polytetrafluoroethylene) to prevent escape. Colonies were housed in incubators at $25^{\circ} \mathrm{C}$ for L. niger and to $30^{\circ} \mathrm{C}$ for L. neoniger . Colonies were overwintered at $10^{\circ} \mathrm{C}($ L. niger $)$ and $15^{\circ} \mathrm{C}$ (L. neoniger ) for two and one months, respectively, between January and February 2018. An acclimatization phase of 15 days prior and post overwintering period was allowed for gradual temperature transition. The higher temperature used in L. neoniger was due to concurrent experiments carried out with multiple, ecologically different, species.

\section{General Data Analysis}

All analysis and modelling were conducted for each species separately as the aim of this research was not to compare the species but to study the effects of the treatments simultaneously for both of them.

All data analysis was done in $\mathrm{R}$ version 3.6.2 (R Core Team, 2019). Type-II analysis of variance tables based on 1-d.f. chi square tests were used to assess the significance of terms in all models (e.g. lm, glm, lme) using the 'Anova' function in the "car" library (Fox \& Weisberg, 2018); these tests are marginal, i.e. each term is tested in presence of all other terms in the model and tests are not order-dependent. Data were summarized using libraries plyr (Hadley Wickham, 2010), dplyr (H Wickham, 2018) and Rmisc (Hope, 2013). Figures were made after the means and confidence intervals calculated from the raw data using ggplot2 (Hadley Wickham, 2016) with RColorBrewer (Neuwirth \& Brewer, 2014).

\section{Colony Growth}

A pilot experiment was conducted in 2015/16 with L. neoniger. Twenty-four Colonies were monitored over six months; colonies were distributed among three treatments varying in the protein to carbohydrate content of their diet. Colony growth (the number of workers) increased near linearly with increasing parts of carbohydrates, where colonies fed a diet with a P:C ratio of 1:1 produced fewer workers than those fed a diet of 1:2, and those fed a diet of 1:3 produced the greatest number of workers. The experiment also documented that a weekly provision of $\sim 125 \mu \mathrm{l}$ of artificial diet (see below) was sufficient to maintain colony growth and survival. These pilot data informed our choice of the quantity of diet to provision and the P:C range.

Colonies in the present study were randomly assigned to treatments after the first census (approximately one month of growth). The treatments were feeding frequency and diet composition (protein to carbohydrate ratios, abbreviated as P:C henceforth) (Fig. 3). Feeding frequency had three levels: a $125 \mu \mathrm{l}$ aliquot every other week (0.5), every week (1), or twice per week (2). The P:C had four levels representing a linear change in P:C from approximately 1:2 up to 1:16 with increments of rough doubling (see Fig. 3 for details), hereafter referred to as low carbohydrate (L), medium-low (ML), medium-high $(\mathrm{MH})$, and high carbohydrate $(\mathrm{H})$. The starting number of colonies was 96 for $L$. neoniger ( 8 colonies per treatment combination), and 86 for $L$. niger (7-8 colonies per combination).

Portions were $125 \mu \mathrm{l}(127.33 \pm 0.38 \mathrm{mg}$, mean $\pm \mathrm{SD})$ of isocaloric chemically defined diets prepared using casein, whey protein, egg powder and sucrose in agar solution (Dussutour \& Simpson, 2008). Insect vitamins (Vandersant, MP Biomedicals, Germany) and a preservative (Methylparaben, Dephyte, Germany) were also added equally to the diets. For details on the diet constitution and recipes see Table S1. Food leftovers were 
removed after three days and new batches of food were prepared every three weeks. The development of the colonies was monitored over 10 months by counting larvae and workers on a monthly basis. Every colony census was done in a non-invasive way by visually inspecting the test tubes under a stereomicroscope (SZX7, Olympus, USA) at 40X magnification. Colonies were considered 'dead' only if the queen died.

Data were analysed to answer three related questions: 1) Did colony survival vary depending on treatments? 2) Did the dynamics of growth vary with treatments? and 3) Did overall growth vary with treatments?

G-tests (function 'G.test') were used to assess differences in colony survival as related to treatments using the library RVAideMemoire (Hervé, 2014). The 'G.multicomp' function was used for post-hoc comparisons - p-values were corrected for false discovery rate (FDR).

A linear mixed-effects model for each species, function 'lme' from library nlme (Pinheiro, Bates, DebRoy, \& Sarkar, 2014) was used to assess growth dynamics. Growth was approximated as the number of workers in each monthly census, excluding colonies that died. Feeding frequency, diet P:C and census number (the latter as a third-order polynomial, identified after initial visual inspection of the data) were the fixed effects (factorial), and colony ID was expressed as a random factor (96 colonies for L. neoniger and 86 for L. niger ). Additionally, census number was added as a first-order autocorrelation structure (corAR1) grouped by colonies.

To assess the effects of treatments on overall growth we used a two-way analysis of variance with the frequency of feeding and diet P:C as fixed effects and the difference in numbers of workers between the last and second census (i.e. the first census that had experienced the treatments) as the response variable.

\section{Worker Phenotype}

Several different worker traits were measured: head width, dry mass, lean mass and lipids content. These characteristics, individually and in aggregate, are typically responsive to nutrition and change with colonylevel development and health (Smith \& Tschinkel, 2009; Tschinkel, 1993). Head width of young workers (recognized by their lighter colouration, Fig. 2) was used as a proxy of body size (Schwander, Rosset, \& Chapuisat, 2005). Head width images were taken at 56X magnification using a stereomicroscope (SZX7, Olympus, USA) with an attached camera (Retiga 2000R, Q-Imagine, Canada) and measured at the maximal distance across the eyes using iSolutions-Lite software (iMT Technology, USA). The number of ants measured per colony varied due to availability $(8 \pm 2.6$, mean $\pm \mathrm{SD})$. Lipid extractions were done using gravimetry after repeatedly washing the samples with ether; we used the protocol of Tschinkel and Smith (2009). Samples were first dried for $>48 \mathrm{~h}$ at $60^{\circ} \mathrm{C}$. Due to the low mass of Lasiusworkers, we extracted a sample of ants, en masse, for each colony. The number of ants per colony was $8.8 \pm 1.8$ (mean $\pm \mathrm{SD}$ ). The lipid extraction gave three measures, dry mass, lean mass, and the proportion of dry mass that was lipids (i.e., the portion extracted). Both dry mass and lean mass were normalized as the mass of the sample divided by the number of ants in the sample. Linear models ('lm' function) were used to analyse dry mass, lean mass and lipid content; head width was analysed using generalized linear models ('glm' function) with Gamma distribution.

\section{Stable Isotopes Pulse Experiment}

In order to examine the flow of nutrients into a colony, we used a stable isotope pulse. Diets enriched with the heavy stable isotopes ${ }^{15} \mathrm{~N}$ and ${ }^{13} \mathrm{C}$ (when abbreviating carbon with $\mathrm{C}$ we use the superscript for atomic mass in order to differentiate from $\mathrm{C}$ for carbohydrates) were fed once and the flow of the isotopes to different castes was assayed over time. After the final census of $L$. neoniger, a subset of eight colonies in the ML treatment were randomly assigned to either of two treatment groups, those receiving the heavy isotope enriched diet (Table S1) or those receiving an unenriched (but otherwise identical) control diet. Five of the eight colonies were provided with the enriched diet, and the remaining three were fed the unenriched diet in order to control for background isotopic levels. The ML diet used in the previous experiment was modified so that isotopically labelled materials could be easily integrated. The basic methods of Shik et al. 
(2018) were followed. A small quantity of ${ }^{15} \mathrm{~N}$ labelled or unlabelled ammonium nitrate (labelled: Ammonium nitrate-15N, EB0056; unlabelled: Ammonium Nitrate SHBJ1050, Sigma-Aldrich, USA) and a small quantity of ${ }^{13} \mathrm{C}$ labelled or unlabelled glucose (labelled: D-Glucose-1-13C, MBBC0227V; unlabelled: D-(+)-Glucose, SLBJ0583V, Sigma-Aldrich, USA) were added so that the P:C ratio of the diet was not changed. The supplemental ammonium nitrate amounted to $0.9 \%$ (by dry mass) of the protein sources in the diet, and the supplemental glucose was approximately $4 \%$ of the carbohydrate sources in the diet. Colonies were offered $125 \mu \mathrm{L}$ of the diet for $24 \mathrm{~h}$. After this period, the food was removed and a random sample of approximately five workers and five larvae was withdrawn, frozen for $24 \mathrm{~h}$, and then stored in a drying oven at $60^{\circ} \mathrm{C}$ (following the methods of Smith \& Tillberg (2009)). Colonies were then sampled again after $96 \mathrm{~h}$ following the same procedure. Dried samples were homogenized in sterile aluminium capsules and elemental analysis was carried out at the University of California at Davis Stable Isotope Facility using a PDZ Europa ANCAGSL elemental analyser interfaced to a PDZ Europa 20-20 isotope ratio mass spectrometer (Sercon Ltd., Cheshire, UK). The atomic per cent enrichment was calculated as the atomic per cent of the heavy isotope (relative to the lighter isotope) divided by the same quantity for the same sampling time and caste in the unlabelled colonies. The individuals in colonies fed enriched diets, overall, had $9 \%$ more ${ }^{13} \mathrm{C}$ and $71 \%$ more ${ }^{15} \mathrm{~N}$ compared to individuals in colonies fed unlabelled diets. Each element was analysed separately using the atomic per cent excess as the response variable. Time $(24$ vs. $96 \mathrm{~h}$ ) and developmental caste (worker vs. larva) were the categorical predictors. Due to heterogeneity of variances, these data were analysed using a Kruskal-Wallis test followed by a Dunn test ('dunnTest' function in the FSA library (Ogle, 2018)) for pairwise differences using the Benjamini-Hochberg method.

\section{Diet preference under field and lab conditions}

Field trials were conducted between May and June 2018 in grassy lawns for both naturally occurring colonies of L. niger at the Botanical Garden of Münster (51 $\left.57^{\prime} 55.9^{\prime \prime} \mathrm{N} 7^{\circ} 36^{\prime} 22.9^{\prime \prime} \mathrm{E}\right)$, and for L. neoniger on the

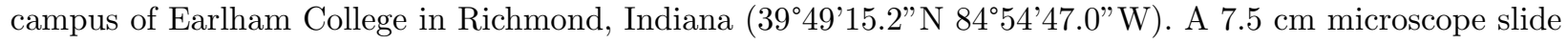
with $125 \mu \mathrm{l}$ portions of all four P:C ratios (as described above) in random order, was placed near an active nest entrance. Baited nest entrances were at least $1.5 \mathrm{~m}$ apart and each was used only once. After placement, the number of ants at each food portion was counted every five minutes during 40 minutes. If other ant species were seen at any food portion at any location, then that time point and all subsequent time points at that location were not included in the analysis. We assumed that all food portions had an equal probability of discovery.

After food preference for the four P:C levels had been established, we performed an additional diet choice test with the species $L$. neoniger only. The diet was modified to ascertain whether P:C preference was driven by $\mathrm{P}$ content and/or $\mathrm{C}$ content. Levels of $\mathrm{P}$ were varied (holding $\mathrm{C}$ constant), and then separately, levels of $\mathrm{C}$ were varied (holding $\mathrm{P}$ constant). We used the midpoint for these diets to be the most preferred 'ML' diet (see Fig. 3) and then halved and doubled either $\mathrm{P}$ or C. We then presented three sets of diets to field and lab colonies (as above) - all paired diets had either constant $\mathrm{C}$ or constant $\mathrm{P}$ (i.e. they were either on the vertical or the horizontal black line in Fig. 3).

Diet preference data collected from field colonies were square-root transformed, in order to homogenize variances, and analysed using a mixed-effect model to take into account the non-independence of repeated counts at each colony. The model included the "bait" type (i.e., the diet P:C) as a fixed factor, and colony ID as a random factor (18 colonies for L. neoniger and 23 for L. niger ). A first-order autocorrelation structure (corAR1) was specified as "Time / colony ID / bait type". As above, the 'lme' function from the nlme library (Pinheiro et al., 2014) was used to analyse data.

Food preference trials were also conducted on two laboratory-reared $L$. neoniger colonies (c.a. two years old with over one hundred workers). Food portions were placed in foraging arenas attached to colony containers and then foraging was filmed using iPhones and the Lapse-It application for time-lapse. Pictures were taken every 5 minutes for at least 3.5 hours and all ants at each bait were counted for every time period. Laboratory data were not statistically analysed due to low sample size. Both colonies showed the same preference to 
the four diet ratios, but only one colony of the pair responded with high recruitment to the variable $\mathrm{P}$ and $\mathrm{C}$ diets (Fig. S1).

\section{RESULTS}

\section{Colony Survival and Growth}

The first census of colony growth was in August 2017 and the last in April 2018 (months spent overwintered were not included in the analysis). Colony survival was affected only by diet treatment in L. neoniger ( $\mathrm{G}$ $=9.19$, df $=3, P=0.03$, Fig. 4a), but neither species showed an effect of feeding frequency on survival. Only the diet low in carbohydrates $(\mathrm{L})$ showed decreased survival relative to all other treatments $(P<0.05$ in all comparisons after FDR correction). For both species, each fixed effect (diet P:C, feeding frequency and time) in the mixed-effects model was statistically significant, as were the interactions Time*Diet and Time*Frequency (Fig. 5, Table S2). The latter two-way significant interactions suggest that the dynamics of diet P:C and feeding frequency changed with time, some of which were likely due to differences becoming more pronounced over time. Additionally, species-specific effects on growth were apparent from the non-recovery of L. neoniger colonies post-winter, especially due to differential survival (above).

In the analysis of overall growth, diet P:C and feeding frequency were statistically significant for both species, but there were no significant interactions (Fig. 4b, Table S3). The high carbohydrate diet (H) produced the lowest growth, differing from the low carbohydrate $(\mathrm{L}, P<0.05)$ and medium-high carbohydrate $(\mathrm{MH}, P<$ $0.005)$ diets in post-hoc comparisons. The frequency that colonies were fed was highly significant, with only colonies fed every other week suffering reduced growth relative to the other two treatment levels $(P<0.001$ in both post-hoc comparisons). Colonies of $L$. niger grew larger than colonies of L. neoniger, seemingly owing to differences in overwintering and recovery from winter

\section{Worker Phenotypes}

Differences among treatments in worker phenotypes are summarized in Fig. 6 for both species and full results are given in Table S4. All measured traits were significantly affected by diet P:C and feeding frequency separately in L. niger, but only head width exhibited a significant diet P:C x Frequency interaction. In L. neoniger, worker lean mass and lipid content were affected by diet P:C only, whereas head width was affected by feeding frequency only. L. neoniger worker dry mass was the only trait affected by both diet $\mathrm{P}: \mathrm{C}$ and feeding frequency, and no interactions were significant for all the measured traits of this particular species.

Overall, increasing protein content in diet increased head width, lean and dry mass (Fig. 6). But as noted above, the effect was the opposite for worker lipid content. Although L. neoniger head width was not affected by diet $\mathrm{P}: \mathrm{C}$, the directional difference in means is consistent with the results obtained for lean and dry mass (i.e., more proteinaceous diets correspond to larger workers).

In addition, while feeding frequency only had a statistically significant effect on $L$. neoniger worker dry mass (both higher frequency treatments were marginally different than the lower frequency, $P=0.06$ and $P=$ 0.08), the direction of the effect was consistent across all dependent variables assessed for both species (Fig. $6)$ - more frequent feedings (i.e., greater food availability) led to larger and fatter individuals.

\section{Stable Isotope Pulse Experiment}

There was a statistically significant effect of caste by sample time for atomic enrichment of both ${ }^{15} \mathrm{~N}$ and ${ }^{13} \mathrm{C}$ (K-W test, $\chi^{2}>12$, d.f. $=3, P<0.005$ for both ${ }^{15} \mathrm{~N}$ and ${ }^{13} \mathrm{C}$ ). It can be noticed that incoming nutrients are first ingested by workers, with worker atomic per cent of ${ }^{15} \mathrm{~N}$ and ${ }^{13} \mathrm{C}$ peaking at $24 \mathrm{~h}$. The $24 \mathrm{~h}$ workers had nearly double the atomic enrichment of ${ }^{13} \mathrm{C}$ compared to all other treatments and had five-fold higher 
enrichment of ${ }^{15} \mathrm{~N}$ (Fig. 7). Workers were statistically different $(P<0.05)$ from larvae at both 24 and 96-hour collections for ${ }^{15} \mathrm{~N}$, but the difference was not statistically significant in the 24-96 hour comparison for ${ }^{13} \mathrm{C}$. No other pairwise comparisons were statistically significant. We had predicted that we would see a movement of more nitrogen to larvae relative to carbon, but this was not evident in the data. However, if anything the opposite appears more likely. Larval atomic per cent ${ }^{15} \mathrm{~N}$ remained constant over both sample times while the mean for atomic per cent ${ }^{13} \mathrm{C}$ increased over sampling points (this result is trending toward being statistically significant, $P=0.11$ ). Larval $\mathrm{C}$ :N was much higher than that of adult workers, $7.24 \pm$ 0.18 vs. $5.00 \pm 0.11$ (mean $\pm \mathrm{SE}, \mathrm{F}_{1,39}=108.9, P<0.001$ ), likely due to the high lipid content of larvae. Thus, despite a high protein need relative to workers for growth, the carbohydrate needs of larvae were substantial.

\section{Diet preference}

About 20 baiting trials were conducted for each species in the field, but several time intervals and bait stations had to be discarded due to intrusion by other species or a lack of Lasius presence. L. niger clearly tended to avoid the diet with the highest protein content (termed "L" in this study because of the low carbohydrate content) but did not differentiate among the remaining diets (Fig. 8), although pair-wise comparisons revealed that ML and $\mathrm{MH}$ were significantly preferred over $\mathrm{L}(\mathrm{P}<0.05)$. On the other hand, L. neoniger exhibited an overwhelming preference for the ML diet, with diet being highly significant in the mixed-effects model $\left(\chi^{2}=52.01, P<0.001\right)$. This trial was also replicated with two L. neoniger (ca. 2 years) lab colonies, and the result was qualitatively similar (data not shown).

In order to understand whether the preference for ML was driven by the numerator (carbohydrates) or the denominator (protein) in the ratio, we offered new baits with both macronutrients to L. neoniger field colonies, yet in series where only one varied. We hypothesized that the preference for ML was a composite of a combined preference for carbohydrates and proteins, especially because their response to the gradient in ratios was non-linear. When carbohydrates were held constant the ants had a strong preference for lower levels of protein; the number of ants present with the least amount of protein was double that compared to the most protein. The intermediate level of protein received an intermediate level of visitation. The lab results were consistent with the field data. The effect of diet in these trials was again highly statistically significant $\left(\chi^{2}=29.09, P<0.001\right)$. When protein was held constant, the ants had an increasing preference for more carbohydrates, with the preference increasing with increasing levels of carbohydrates $\left(\chi^{2}=13.47\right.$, $P=0.001)$ (Fig. S1).

\section{DISCUSSION}

We describe a robust pattern where individual and superorganism (i.e. ant colony) growth increased with dietary protein, both as a function of the amount provided and its quantity relative to carbohydrates. This pattern was supported across two independent experiments on two common ant species in central Europe and the midwestern United States. These results support our hypothesis that colony size and the size of individuals within colonies are protein limited. Availability of protein likely constrains colony growth and is also a possible regulator of size and caste determination within colonies.

We also show evidence of nutrient trade-offs for colony growth and survival, as well as for individual size and lipid storage. A visual schematic of nutrient trade-offs is depicted in Fig. 1, such that for a particular trait there is a single optimal P:C. Trade-offs exist when different traits have different optima, namely, when the lines representing trait values over differing $\mathrm{P}: \mathrm{C}$ values intersect. The lines for both colony (growth vs. survival) and individual traits (size vs. lipid content) intersect in our data (Fig. 9). The area of intersection represents the optimal investment, assuming that each of the traits has equal fitness effect. For both individual and colony-level traits, for both species, the intersection is at the level of the intermediate $\mathrm{P}: \mathrm{C}$ used in this study. Interestingly, we may have detected the optimum P:C for both colony survival and 
growth; that is, intermediate $\mathrm{P}: \mathrm{C}$ levels have the highest value of both survival and growth. On the other hand, the maximum values for the individual-level traits of size and lipid content are at the extreme P:C levels used in this study - the largest workers were produced at the highest relative $\mathrm{P}$ and the fattest workers at the highest relative $\mathrm{C}$. The existence of trade-offs at the individual level suggest that colonies can manipulate the nutrients available to individuals within a nest in response to a changing external environment. For example, in response to environmental stress, colonies may modify the nutrients available to individuals within the nest, biasing provisioning toward carbohydrates over protein. At the colony level, a nutritionally mediated trade-off between growth and survival implies that selection may optimize nutrient collection to benefit the life-history trait most beneficial at a given time in the life cycle (including having variable strategies for nutrient collection).

\section{Development of ant colonies}

Individual workers and colonies (superorganisms) increased in size with increasing amounts of protein in the diet, and as a function of how much food was available, and yet there was no interaction between the two (Figs. 4-7, 9). However, the high mortality exhibited by L. neoniger colonies under one of the experimental diets (L) is consistent with other studies that find either lesser stress resistance or nitrogen toxicity in high protein/low carbohydrate diets (Fig. 4)(Cook, Eubanks, Gold, \& Behmer, 2010; Dussutour \& Simpson, 2009, 2012). We hypothesize that the high colony mortality was due to a decrease in lipid stores, as individual lipid content is a buffer for colony survival (Dussutour, Poissonnier, Buhl, \& Simpson, 2016; Christopher $\mathrm{R}$ Smith, 2007). The lower survival in L. neoniger, but not L. niger, with the highest protein (L) diet may be due to different overwintering conditions for each species. L. neoniger was overwintered at a higher temperature compared to L. niger (although the temperature transition was the same for both species) and thus workers may have had higher metabolic rates and depleted greater amounts of their lipid reserves, leading to higher worker and colony mortality. In agreement with our data, lipid storage in other insects is increased with increased carbohydrate content of diet (Dussutour et al., 2016; Warbrick-Smith, Behmer, Lee, Raubenheimer, \& Simpson, 2006). Note, the higher temperature used in L. neoniger was due to the concurrent overwintering of multiple, ecologically different, species.

Other studies have demonstrated that a change in the macronutrient ratios, toward a higher protein content, has toxic effects (Dussutour \& Simpson, 2009, 2012; Harrison, Woods, \& Roberts, 2012; Simpson \& Raubenheimer, 2009). However, the P:C ratios in our study were all relatively high compared to studies documenting toxicity - increased protein content in our study was generally correlated with both increased worker number and worker size. A decrease in colony growth with even higher levels of protein was found in our preliminary study, which may have been due to a toxicity effect. Together, our preliminary data and the data presented in this paper suggest that optimal growth is achieved through a trade-off between sufficient carbohydrates for lipid storage on the one hand, and enough protein for growth on the other (but less than will cause toxicity). In both Lasius species, this optimum appears to be at a P:C of 1:4 to 1:8. These results are consistent with previous studies using similar diets, though those studies measured mortality rather than reproduction - mortality was lowest between 1:3 and 1:5 in Rhytidoponera sp., L. nigerand Solenipsis invicta (Cook et al., 2010; Dussutour \& Simpson, 2009, 2012).

Colony growth was non-linear with respect to the amount of food provided. Colonies fed once per week did not grow any better than those fed twice weekly, suggesting that we found a maximum growth rate for colonies on the provided diets. Doubling food availability essentially saturated their ability to turn those nutrients into new ants. Colonies fed only once every two weeks, however, had decreased growth. Therefore, our levels of nutrient provisioning were appropriate to assess nutrient limitation as a function of both the amount and P:C ratio of provided diets. 


\section{Colony and Individual Phenotypes}

Our study demonstrated that average ant size increased with increasing protein (relative to carbohydrates) and the total amount of diet provided. While we did not examine gene expression in this study, it has been established that caste determination in some social insects is regulated behaviourally and morphologically by nutrient-sensing genes, including those involved in insulin and Tor signalling (Wheeler, Buck \& Evans 2006; Patel et al. 2007; Toth et al. 2007; and reviewed in Chandra et al., 2018; Smith, Toth, Suarez, \& Robinson, 2008; Toth \& Robinson, 2007), and caste determination is largely explained by size variation (Trible \& Kronauer, 2017). Thus, a universal feature of 'organismality' is that size scales with the nutritional environment during development because the translation of nutrients into growth is achieved through conserved processes at the cellular level. If there existed a super-superorganism then we would also expect that its size, along with the size of its constituent parts, is nutritionally regulated; note that supercolonies, as seen in some ant species (Holway, Lach, Suarez, Tsutsui, \& Case, 2002), do not likely fit the evolutionary definition of 'organism'.

While worker size (such as head width or lean mass) was regulated by the quantity of protein in the environment, individual lipid content was regulated by the amount of carbohydrates (Fig. 6). As noted above, there was thus a trade-off faced by organisms with regard to their nutritional choices for these two major macronutrients (Fig. 9). Solitary insects, including caterpillars and last instar grasshoppers, tend to maximize growth with P:C near 1:1 (reviewed in Behmer 2009), whereas flies performed better with a more carbohydrate bias (Lee et al., 2008; Young, Buckiewicz, \& Long, 2018). It is clear that in these studies there are life-history trade-offs inherent in different $\mathrm{P}: \mathrm{C}$ ratios, such as longevity (maximized with increasing decreasing protein) and egg-laying (higher at increased protein).

While data are currently limited across insect taxa, we hypothesize that superorganism growth is maximized at a higher carbohydrate diet compared to most solitary insects. This prediction is premised on the majority of the standing biomass of a superorganism being non-growing, non-reproducing workers. While larvae have a higher carbon to nitrogen $(\mathrm{C}: \mathrm{N})$ ratio than workers, this is largely due to their high lipid content. The colony's germline, reproductive gynes and males, have a higher nitrogen content (i.e., much lower C:N ratio) (Schmidt et al., 2012; C R Smith et al., 2008; Chris R Smith \& Suarez, 2010). A logical extension of this prediction is that social insect growth and development is less protein limited than solitary insects and this may have been an inherent benefit to social living. This hypothesis is in line with how metabolic rate scales with body size in insect organisms and superorganisms. On a per mass basis, metabolism scales constantly across solitary and social insects (Hou, Kaspari, Vander Zanden, \& Gillooly, 2010). Thus, eusociality and increased colony size are selectively advantageous with regard to increased metabolic efficiency.

\section{Nutrient flows within colonies and colony-level preferences}

We predicted that larvae would receive incoming protein, disproportionately, compared to carbohydrates and that the opposite would be true for workers. Using stable isotope labelling of the most preferred and optimal diet of L. neoniger, fed as a pulse, we traced nitrogen (as a proxy for protein) and carbon (as a proxy for carbohydrates) through colonies over four days. As is necessarily the case, nutrients were transferred from workers to larvae, but the signature of excess isotope enrichment in workers was gone in four days. Contrary to our expectation, after four days there were no differences between workers and larvae for either nutrient, and there, if anything (the result is marginally statistically significant), was the opposite pattern of nutrient transfer than predicted with larvae having slightly more of an excess of carbon than workers, but not nitrogen. Both workers and larvae at four days still showed atomic excess of labelled isotopes of both elements compared to colonies fed unenriched diets (i.e., they still had labelled nitrogen in/on their body). It is possible that proteins were being stored in workers until larvae were hungry - the timeframe of our study was insufficient to examine differences between developmental castes in diet assimilation. Additional studies using the basic isotope pulse strategy employed here, but with more time-points and a higher resolution of sampling, will help disentangle some of the complex interactions within colonies that are difficult to infer 
from behaviour, such as the relative distribution of nutrients to different sub-groups within a nest, and how rapidly they are distributed and assimilated (Shik et al., 2018).

Workers are non-growing, and thus feed primarily on carbohydrates to fuel their metabolism. As discussed above, we show that colony growth is maximized at intermediate levels of protein in the diet. When given choices of the same diets used to assay colony growth, colony preference was not in alignment with the optimum for colony growth in L. niger - higher protein diets increased growth, but higher carbohydrate diets were preferred. In $L$. neoniger, on the other hand, colony preference was uncannily aligned with optimal colony growth (data were consistent between field and lab colonies). Further work done only withL. neoniger found that preference for protein and carbohydrates in the diet is a result of clear preferences for each of the varying macronutrients, and thus the ants are judging the ratio. When each protein and carbohydrates were manipulated individually, the ants had a clear preference for increasing carbohydrates and for decreasing amounts of protein. What caused a decrease in preference at the higher levels of carbohydrates in the first preference experiment on L. neonigeris unclear, but the effect persisted across multiple preparations of the diets and was consistent in the lab and field (Fig. 8, Fig. S1).

It is difficult to draw generalizable conclusions from a single (one-season) diet/bait preference assay, and it is also difficult to judge optimality in diet from growth only under laboratory conditions. That being said, increased carbohydrate preference by foragers may be an adaptive strategy because this prioritizes survival over growth, and ant colonies tend to be long-lived. For example, when starved, colonies will prioritize investment in growth over investment in reproduction (Smith, 2007), presumably because they will have future attempts at reproduction should they survive the current period of low resource levels. Preference/foraging, though, may not be optimal due to many types of constraints (Pyke, 1984), and studies on some ants have failed to tightly link forager preference with productivity/fitness (Seal \& Tschinkel, 2007). Foragers are responsive to the presence of larvae in the nest and adjust the collection of resources to more protein in their presence (Cassill \& Tschinkel, 1999; Dussutour \& Simpson, 2009). Therefore, it is not as though overall colony preference, as expressed through foragers, is not regulated by feedback. Furthermore, ants are capable of filtering nutrients once foragers return to the colony. Although in non-social organisms this mechanism would be composed mainly by selective absorption of nutrients and excretion of excess, ants use the larvae as a protein stomach and the nutrients are distributed across nest members (Deby L Cassill, Butler, Vinson, \& Wheeler, 2005; Sorenşen, Busch, \& Vinson, 1985; E. O. Wilson, 1976), or to stores/trash enriched with protein (Dussutour \& Simpson, 2009).

\section{Conclusion}

We have shown that protein limitation scales up to limit the size of both organisms and superorganisms. The selective benefits of size, such as task efficiency, longevity, and metabolic efficiency, also trade-off with physiological resource storage. These factors are predicted to select for tuning of dietary preferences, and we found evidence of dietary preference - and ants appear to make decisions on the diet by assessing multiple ingredients independently. The mechanisms by which superorganisms integrate nutritional information and translate nutrition into growth decisions, including feedbacks, are only beginning to be elucidated.

\section{ACKNOWLEDGEMENTS}

We would like to thank D. Ott for fruitful discussions on insect nutrition and stoichiometry, and T. Czaczkes for valuable insights on colony housing and maintenance. We are grateful to J. Gadau, K-H. Knorr and T. Schmidt for kindly providing materials to YG. Preliminary colony growth data for L. neoniger was collected by B. Crawley and M. Saleh. Additionally, M. Bailey, I. Barrera Lopez, D. Neumeister, E. Nicholson, S. Pant, E. Perkins, S. Slavinskas, A. Serna and M. Zenker all helped with this study through ant care and data collection.

Author contributions: CRS and YG designed the experiment. YG, TP, AAW and HM collected the data. YG, CRS and CS analysed the data. YG and CRS wrote the manuscript, which was revised and approved 
by all of the authors.

\section{Funding}

Financial support to YG was provided by Colciencias - Colombia (doctoral studies abroad program, 6792014). Funding to CRS was provided by Earlham College through the Ford-Knight Student-Faculty Collaborative Research Grant, and the Summer Science Research Fund.

Competing Interests: The authors declare that they have no competing interests.

Ethical approval: All applicable national guidelines for the care and use of animals were followed. Permission for L. nigercollection was granted by the city of Münster (67-20-0032, 2017).

Data availability: all raw data would be made publicly available in the Dryad repository.

\section{REFERENCES}

Behmer, S. T. (2009). Insect herbivore nutrient regulation. Annual Review of Entomology, 54 .

Bono, J. M., \& Heithaus, E. R. (2002). Sex ratios and the distribution of elaiosomes in colonies of the ant, Aphaenogaster rudis.Insectes Sociaux , 49 (4), 320-325.

Cassill, Deby L, Butler, J., Vinson, S. B., \& Wheeler, D. E. (2005). Cooperation during prey digestion between workers and larvae in the ant, Pheidole spadonia. Insectes Sociaux , 52 (4), 339-343.

Cassill, Deby Lee, \& Tschinkel, W. R. (1999). Regulation of diet in the fire ant, Solenopsis invicta. Journal of Insect Behavior ,12 (3), 307-328.

Chandra, V., Fetter-Pruneda, I., Oxley, P. R., Ritger, A. L., McKenzie, S. K., Libbrecht, R., \& Kronauer, D. J. C. (2018). Social regulation of insulin signaling and the evolution of eusociality in ants.Science, 361 (6400), 398-402.

Conlon, I., \& Raff, M. (1999). Size control in animal development.Cell , 96 (2), 235-244.

Cook, S. C., Eubanks, M. D., Gold, R. E., \& Behmer, S. T. (2010). Colony-level macronutrient regulation in ants: mechanisms, hoarding and associated costs. Animal Behaviour , 79 (2), 429-437.

Dussutour, A., Poissonnier, L.-A., Buhl, J., \& Simpson, S. J. (2016). Resistance to nutritional stress in ants: when being fat is advantageous. Journal of Experimental Biology, 219 (6), 824-833.

Dussutour, A., \& Simpson, S. J. (2008). Description of a simple synthetic diet for studying nutritional responses in ants.Insectes Sociaux , 55 (3), 329-333.

Dussutour, A., \& Simpson, S. J. (2009). Communal nutrition in ants. Current Biology , 19 (9), 740-744.

Dussutour, A., \& Simpson, S. J. (2012). Ant workers die young and colonies collapse when fed a high-protein diet. Proceedings of the Royal Society of London B: Biological Sciences , rspb20120051.

Fox, J., \& Weisberg, S. (2018). An R Companion to Applied Regression . Sage Publications.

Fox, J., Weisberg, S., Friendly, M., Hong, J., Andersen, R., Firth, D., .. Fox, M. J. (2018). Package 'effects.'

Goetsch, W. (1937). Die Entstehung der ,,Soldaten "im Ameisenstaat.Naturwissenschaften , 25 (50), 803808.

Harrison, J. F., Woods, H. A., \& Roberts, S. P. (2012). Nutrition, Growth, and Size. In Ecological and environmental physiology of insects (Vol. 3). Oxford University Press.

Herve, M. (2014). RVAideMemoire: diverse basic statistical and graphical functions. $R$ Package Version 0 , 9-62. 
Holldobler, B., \& Wilson, E. O. (2009). The superorganism: the beauty, elegance, and strangeness of insect societies. WW Norton \& Company.

Holway, D. A., Lach, L., Suarez, A. V, Tsutsui, N. D., \& Case, T. J. (2002). The causes and consequences of ant invasions. Annual Review of Ecology and Systematics , 33 (1), 181-233.

Hope, R. M. (2013). Rmisc: Ryan miscellaneous. R Package Version ,1 (5).

Hou, C., Kaspari, M., Vander Zanden, H. B., \& Gillooly, J. F. (2010). Energetic basis of colonial living in social insects. Proceedings of the National Academy of Sciences , 200908071.

Hunt, J. H., \& Nalepa, C. A. (1994). Nourishment and evolution in insect societies. Westview press Boulder, $\mathrm{CO}:$

Klotz, J. H. (2008). Urban ants of North America and Europe: identification, biology, and management . Cornell University Press.

Lee, K. P., Simpson, S. J., Clissold, F. J., Brooks, R., Ballard, J. W. O., Taylor, P. W., .. Raubenheimer, D. (2008). Lifespan and reproduction in Drosophila: new insights from nutritional geometry.Proceedings of the National Academy of Sciences ,105 (7), 2498-2503.

Metzl, C., Wheeler, D. E., \& Abouheif, E. (2018). Wilhelm Goetsch (1887-1960): Pioneering studies on the development and evolution of the soldier caste in social insects. Myrmecological News , 26 , 81-96.

Neuwirth, E., \& Brewer, R. C. (2014). ColorBrewer palettes. R Package Version, 1.

Ogle, D. H. (2018). FSA: fisheries stock analysis. R package version 0.8. 20.9000 .

Passera, L. (1974). Differenciation des soldats chez la FourmiPheidole pallidula Nyl.(Formicidae Myrmicinae). Insectes Sociaux ,21 (1), 71-86.

Patel, A., Fondrk, M. K., Kaftanoglu, O., Emore, C., Hunt, G., Frederick, K., \& Amdam, G. V. (2007). The making of a queen: TOR pathway is a key player in diphenic caste development. PloS One ,2 (6), e509.

Pinheiro, J., Bates, D., DebRoy, S., \& Sarkar, D. (2014). R Core Team (2014) nlme: linear and nonlinear mixed effects models. R package version 3.1-117. Available at $h$ Ttp://CRAN. R-Project. Org/Package= Nlme .

Pyke, G. H. (1984). Optimal foraging theory: a critical review.Annual Review of Ecology and Systematics , 15 (1), 523-575.

Raubenheimer, D., Simpson, S. J., \& Mayntz, D. (2009). Nutrition, ecology and nutritional ecology: toward an integrated framework. Functional Ecology , 23 (1), 4-16.

Schmidt, K. C., Hunt, B. G., \& Smith, C. R. (2012). Queen, worker, and male yellowjacket wasps receive different nutrition during development.Insectes Sociaux , 59 (2), 289-295.

Schwander, T., Rosset, H., \& Chapuisat, M. (2005). Division of labour and worker size polymorphism in ant colonies: the impact of social and genetic factors. Behavioral Ecology and Sociobiology ,59 (2), 215-221.

Seal, J. N., \& Tschinkel, W. R. (2007). Complexity in an obligate mutualism: do fungus-gardening ants know what makes their garden grow? Behavioral Ecology and Sociobiology , 61 (8), 1151-1160.

Shik, J. Z., Rytter, W., Arnan, X., \& Michelsen, A. (2018). Disentangling nutritional pathways linking leafcutter ants and their co-evolved fungal symbionts using stable isotopes. Ecology ,99 (9), 1999-2009.

Simpson, S. J., \& Raubenheimer, D. (2009). Macronutrient balance and lifespan. Aging (Albany NY) , 1 (10), 875 .

Simpson, S., \& Raubenheimer, D. (1995). The geometric analysis of feeding and nutrition: a user's guide. Journal of Insect Physiology , 41 (7), 545-553. 
Smith, C R, Anderson, K. E., Tillberg, C. V, Gadau, J., \& Suarez, A. V. (2008). Caste determination in a polymorphic social insect: nutritional, social, and genetic factors. The American Naturalist ,172 (4), 497-507.

Smith, C R, \& Tschinkel, W. R. (2006). The sociometry and sociogenesis of reproduction in the Florida harvester ant, Pogonomyrmex badius. Journal of Insect Science , 6 (1).

Smith, Chris R, \& Suarez, A. V. (2010). The trophic ecology of castes in harvester ant colonies. Functional Ecology , 24 (1), 122-130.

Smith, Chris R, Toth, A. L., Suarez, A. V, \& Robinson, G. E. (2008). Genetic and genomic analyses of the division of labour in insect societies. Nature Reviews Genetics , 9 (10), 735.

Smith, Chris Ray, \& Tillberg, C. V. (2009). Stable isotope and elemental analysis in ants. Cold Spring Harbor Protocols, 2009 (7), pdb-prot5242.

Smith, Chris Ray, \& Tschinkel, W. R. (2009). Ant fat extraction with a Soxhlet extractor. Cold Spring Harbor Protocols , 2009 (7), pdb-prot5243.

Smith, Christopher R. (2007). Energy use and allocation in the Florida harvester ant, Pogonomyrmex badius: are stored seeds a buffer?Behavioral Ecology and Sociobiology , 61 (9), 1479-1487.

Smith, F. (1942). Effect of reduced food supply upon the stature of Camponotus ants. Entomol. News, 53 , 133-135.

Sorenşen, A. A., Busch, T. M., \& Vinson, S. B. (1985). Control of food influx by temporal subcastes in the fire ant, Solenopsis invicta.Behavioral Ecology and Sociobiology , 17 (3), 191-198.

Stearns, S. C. (1992). The evolution of life histories . London: Oxford University Press.

Team, R. C. (2019). A language and environment for statistical computing. Vienna, Austria: R Foundation for Statistical Computing; 2012. URL Https://Www. R-Project. Org .

Toth, A. L., \& Robinson, G. E. (2007). Evo-devo and the evolution of social behavior. Trends in Genetics , 23 (7), 334-341.

Toth, A. L., Varala, K., Newman, T. C., Miguez, F. E., Hutchison, S. K., Willoughby, D. A., ... Hudson, M. E. (2007). Wasp gene expression supports an evolutionary link between maternal behavior and eusociality.Science, 318 (5849), 441-444.

Trible, W., \& Kronauer, D. J. C. (2017). Caste development and evolution in ants: it's all about size. Journal of Experimental Biology , 220 (1), 53-62.

Tschinkel, W R. (1987). Seasonal life history and nest architecture of a winter-active ant, Prenolepis imparis. Insectes Sociaux ,34 (3), 143-164.

Tschinkel, Walter R. (1993). Resource allocation, brood production and cannibalism during colony founding in the fire ant, Solenopsis invicta.Behavioral Ecology and Sociobiology , 33 (4), 209-223.

Tschinkel, Walter R. (1998). Sociometry and sociogenesis of colonies of the harvester ant, Pogonomyrmex badius: worker characteristics in relation to colony size and season. Insectes Sociaux ,45 (4), 385-410.

Warbrick-Smith, J., Behmer, S. T., Lee, K. P., Raubenheimer, D., \& Simpson, S. J. (2006). Evolving resistance to obesity in an insect.Proceedings of the National Academy of Sciences , 103 (38), 14045-14049.

Wheeler, D. E., Buck, N., \& Evans, J. D. (2006). Expression of insulin pathway genes during the period of caste determination in the honey bee, Apis mellifera. Insect Molecular Biology , 15 (5), 597-602.

Wickham, H. (2018). Francois R. dplyr: A Grammar of Data Manipulation. R package version 0.4. 3. 2015 
Wickham, Hadley. (2010). plyr: Tools for splitting, applying and combining data v. 1.4 .

Wickham, Hadley. (2016). ggplot2: elegant graphics for data analysis . Springer.

Wills, B. D., Chong, C. D., Wilder, S. M., Eubanks, M. D., Holway, D. A., \& Suarez, A. V. (2015). Effect of carbohydrate supplementation on investment into offspring number, size, and condition in a social insect. PloS One , 10 (7), e0132440.

Wilson, D. S., \& Sober, E. (1989). Reviving the superorganism. Journal of Theoretical Biology , 136 (3), $337-356$.

Wilson, E. O. (1955). A monographic revision of the ant genus Lasius (Vol. 113). The Museum.

Wilson, E. O. (1976). Behavioral discretization and the number of castes in an ant species. Behavioral Ecology and Sociobiology ,1 (2), 141-154.

Wilson, E. O. (1985). The sociogenesis of insect colonies.Science, 228 (4707), 1489-1495.

Young, Y., Buckiewicz, N., \& Long, T. A. F. (2018). Nutritional geometry and fitness consequences in Drosophila suzukii, the Spotted-Wing Drosophila. Ecology and Evolution , 8 (5), 2842-2851.

Zera, A. J., \& Harshman, L. G. (2001). The physiology of life history trade-offs in animals. Annual Review of Ecology and Systematics ,32 (1), 95-126.
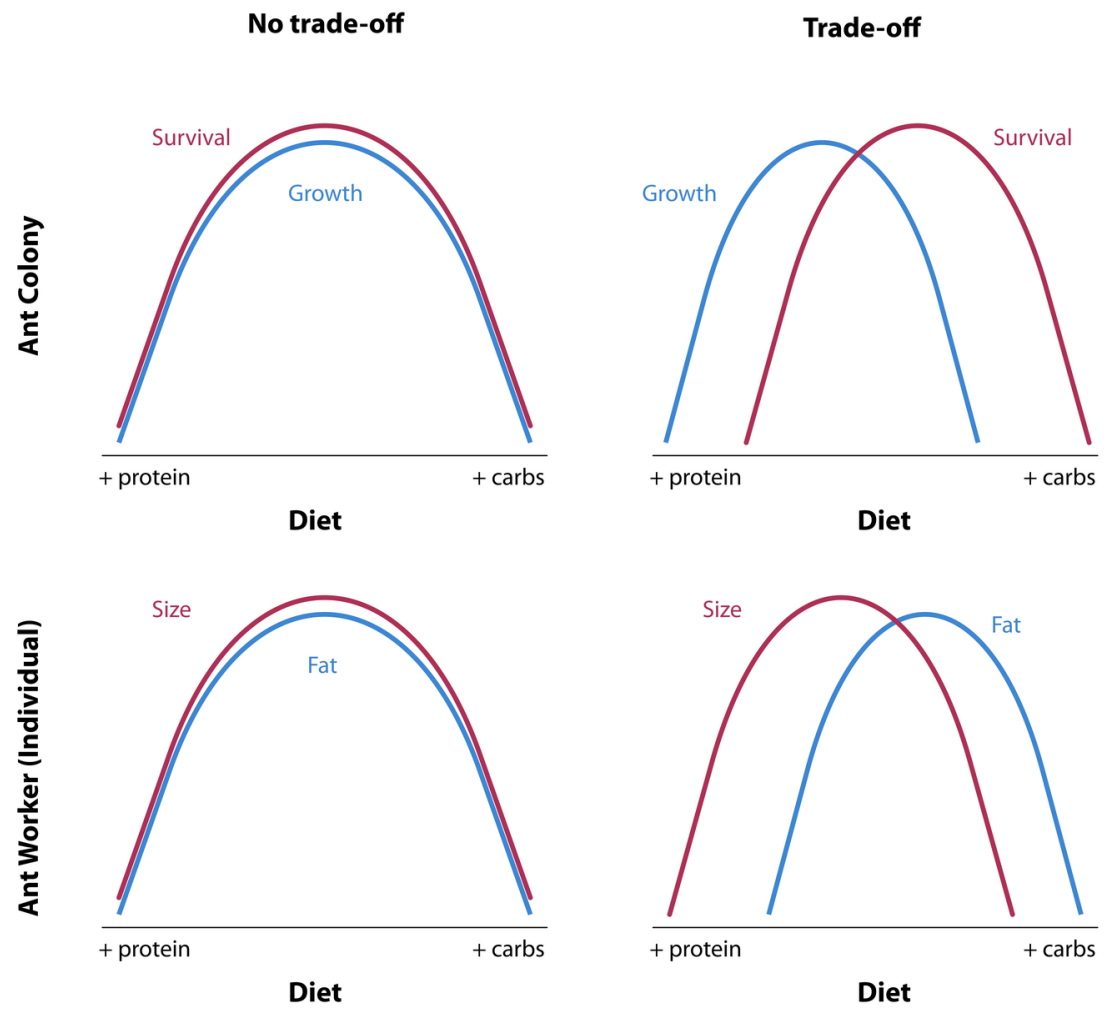

Fig 1. A conceptual schematic of the relationship between nutrient availability/use and trait value for both social colonies (top) and individuals within colonies (bottom). The plots on the left show overlapping optima for different social or individual traits (no trade-off) and the plots on the right show different optima and thus trade-offs (intersecting lines). 


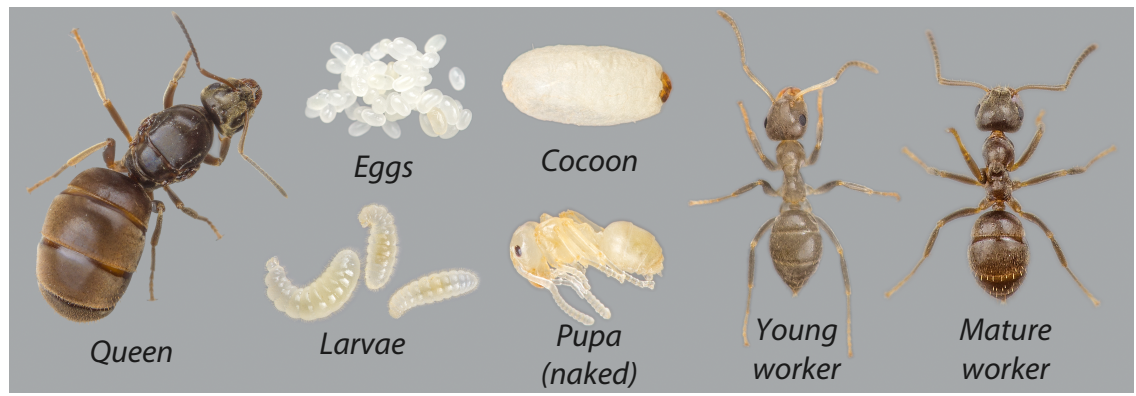

Fig 2. Castes and developmental stages present in aLasius niger colony. Pictures were taken using a Canon 550D camera with a $100 \mathrm{~mm}$ macro-lens and extension rings attached. Figures are not at scale.

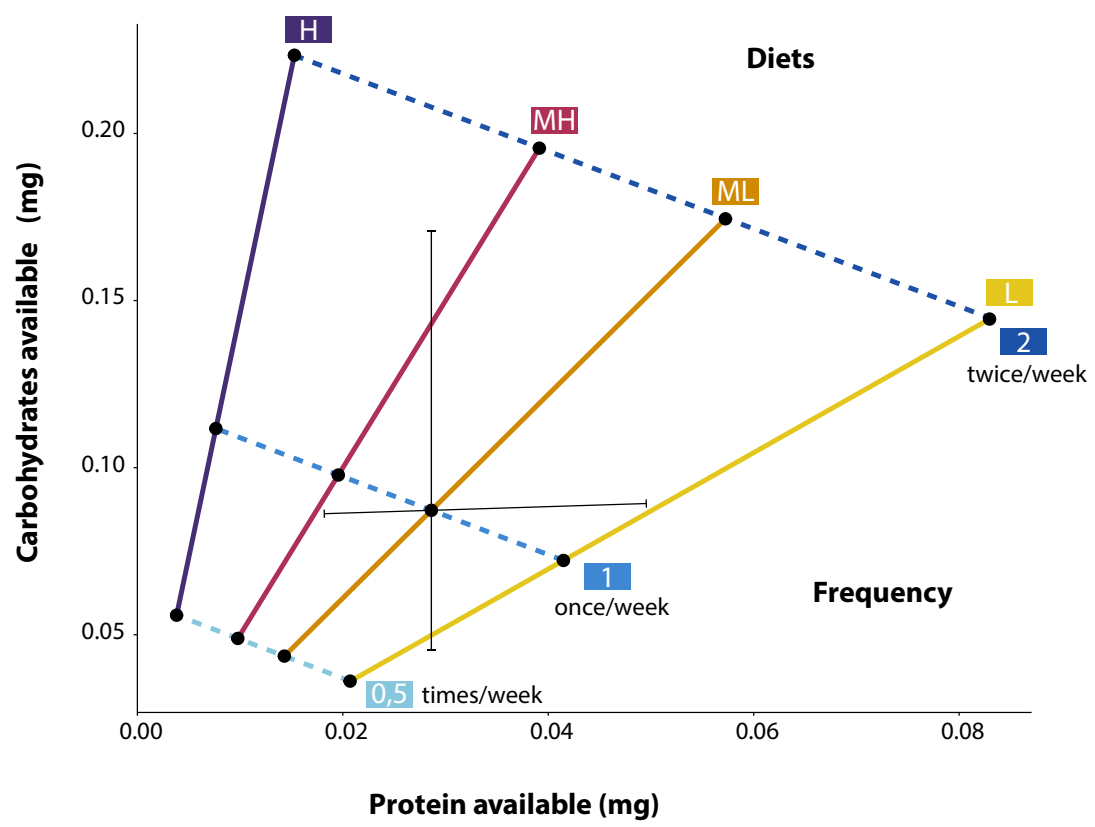

Fig 3. Incipient ant colonies were allocated to twelve experimental treatments (black dots) resulting from the combination of four diets and three feeding frequencies. Values represent weekly available nutrients. L: Low carbohydrate content; ML: Medium-Low; MH: Medium-High; and H: High. Black lines represent the range of protein and carbohydrates used for diet preference assay in field colonies ofLasius neoniger . 


\section{A. Survival}

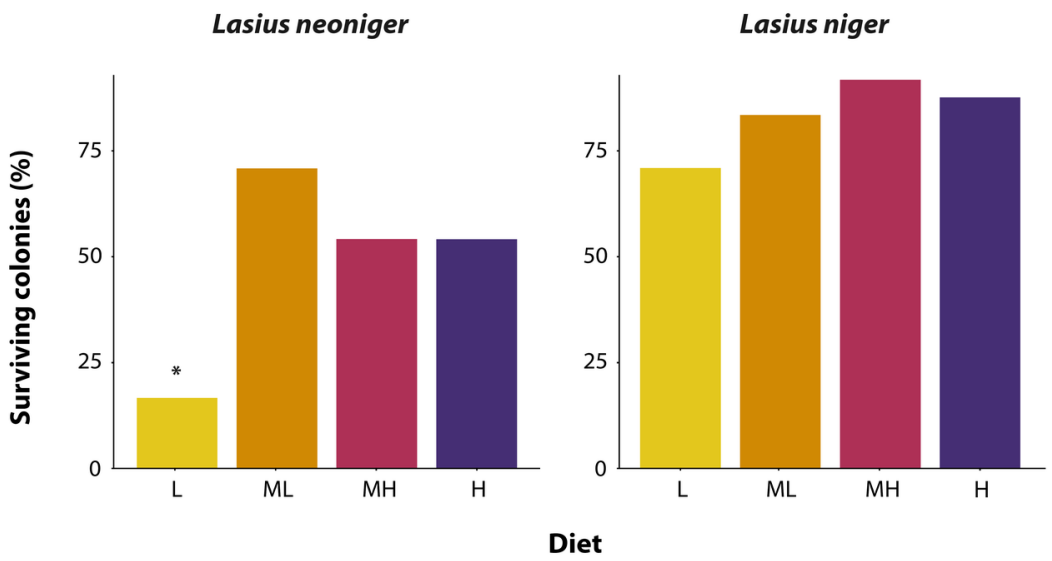

\section{B. Growth}
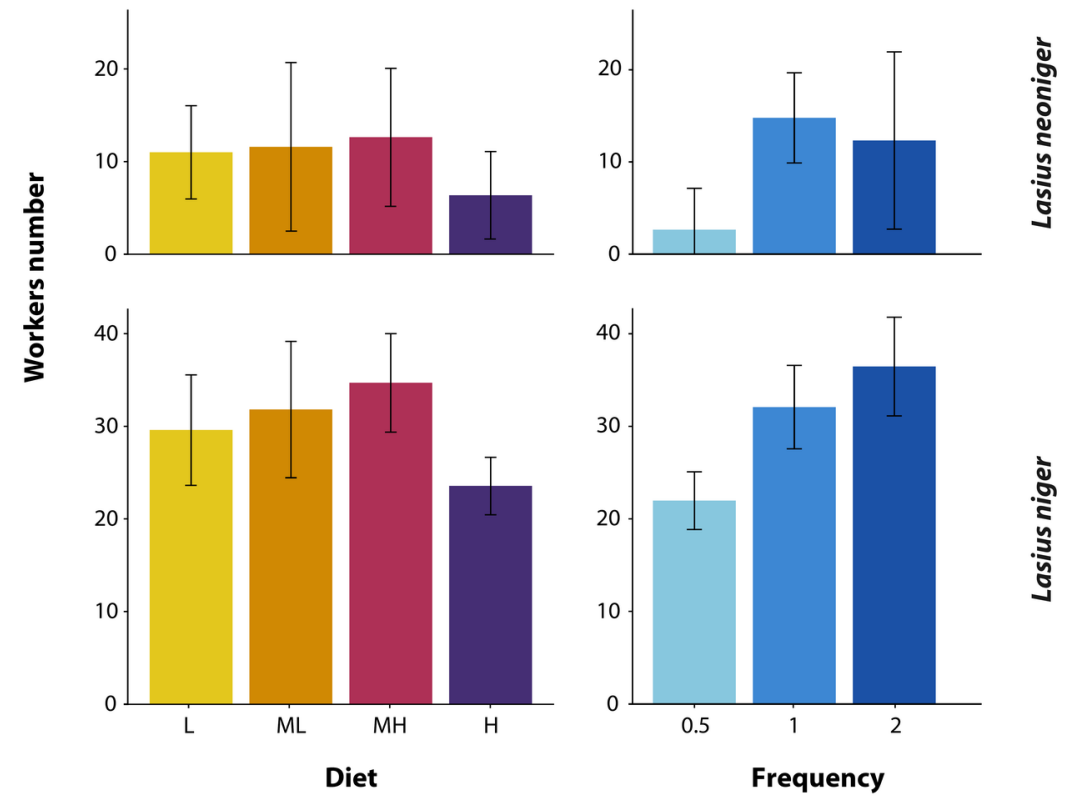

Fig. 4. Colony growth and survival. A) Survival of colonies inL. neoniger was affected by diet composition (Protein:Carbohydrates) but not by feeding frequency. In B) Colony growth was affected by both diet composition as well as diet frequency in both species, but these factors did not interact - the $\mathrm{H}$ diet had lower growth than others, as did the lowest feeding frequency. L: Low carbohydrate content; ML: MediumLow; MH: Medium-High; and H: High. 


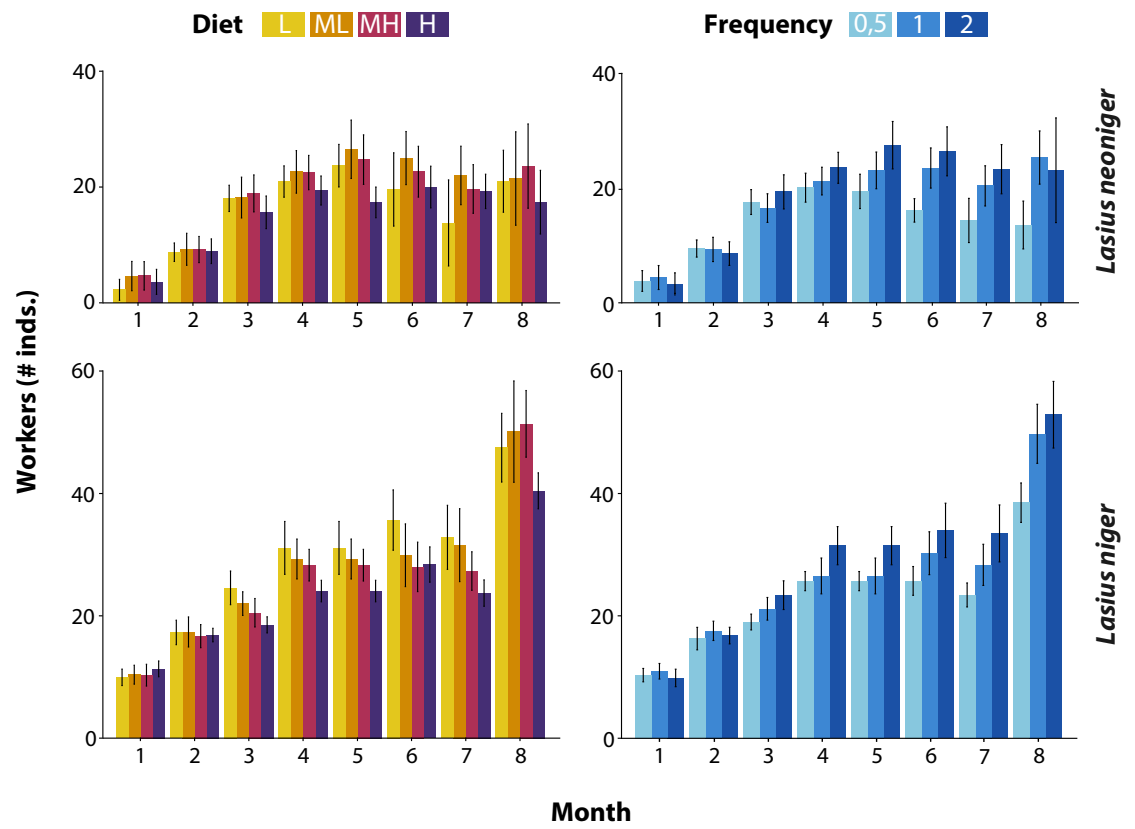

Fig. 5. Colony development was affected by diet composition (Protein:Carbohydrates) and feeding frequency, and the dynamics changed over time. L: Low carbohydrate content; ML: MediumLow; MH: MediumHigh; and H: High. Variation expressed as confidence intervals. Statistical results available in Table S2. 


\section{Lasius neoniger}
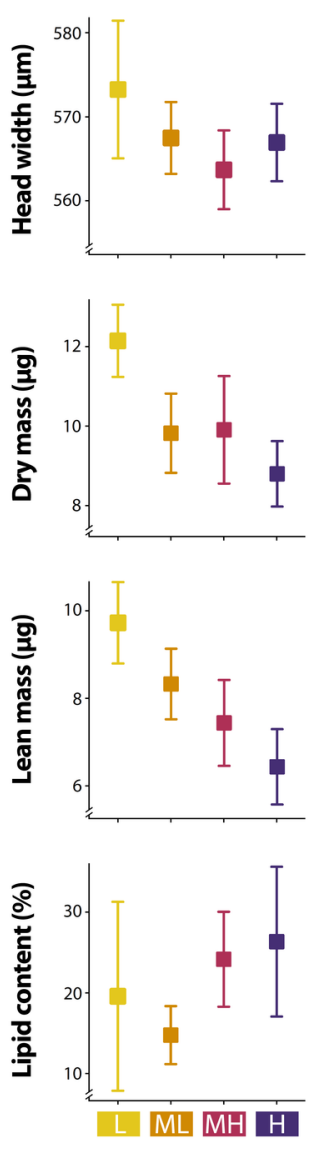

Diet
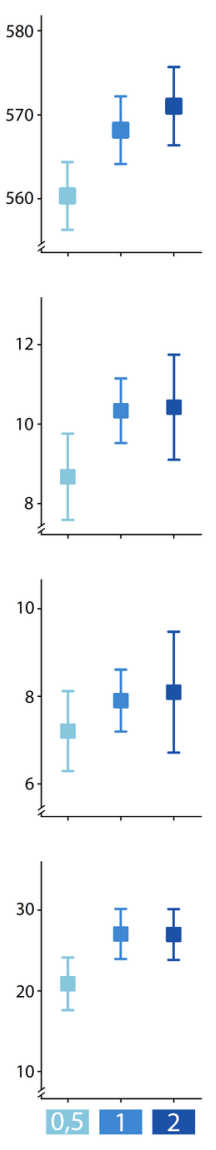

Frequency
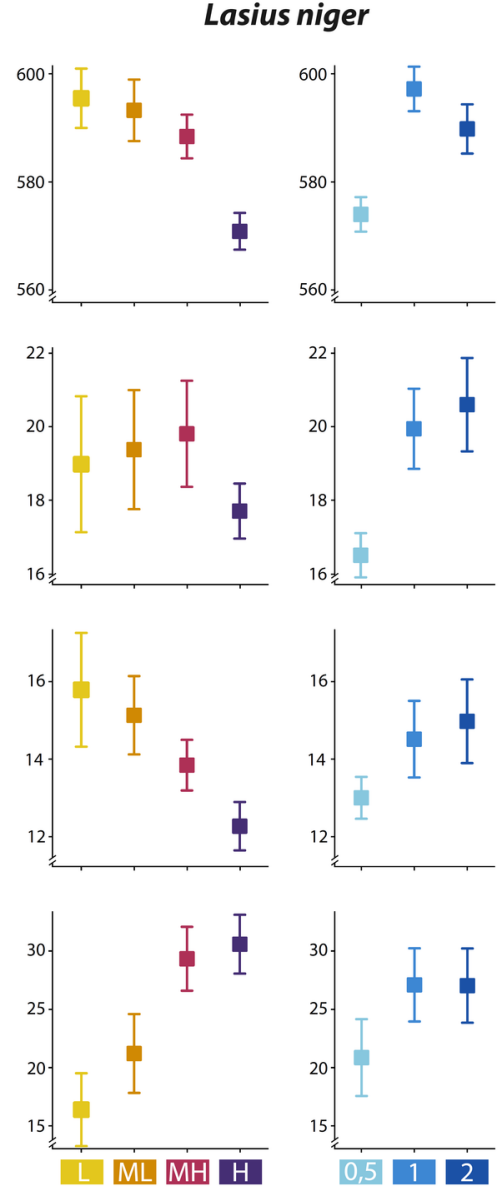

Diet

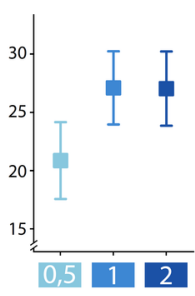

Frequency

Fig 6. Workers phenotypic traits were responsive to diet P:C and feeding frequency. Higher dietary protein led to bigger workers and less lipid storage, and more frequent feeding was associated with bigger workers and increased fat storage. L: Low carbohydrate content; ML: Medium-Low; MH: Medium-High; and H: High. Variation expressed as confidence intervals. Statistical results are available in Table S4.
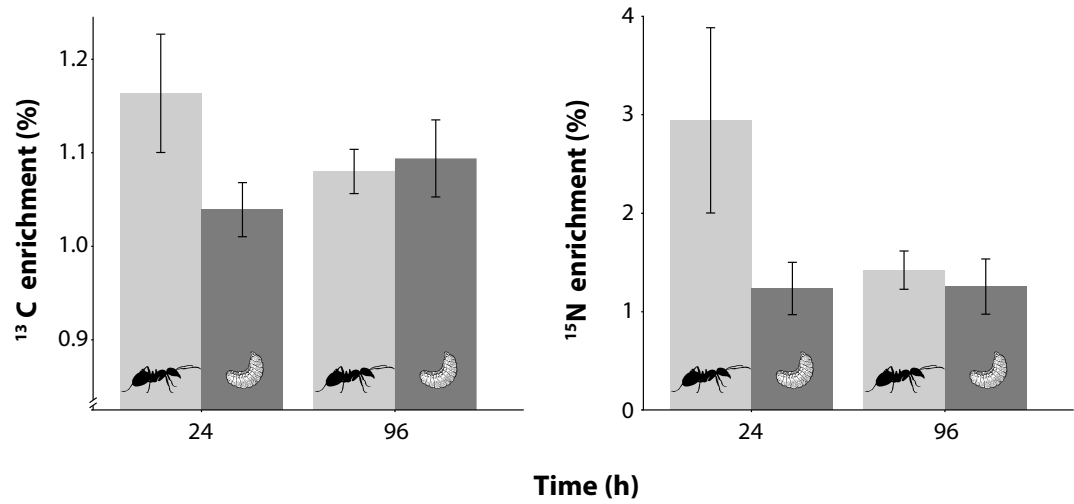
Fig 7. Atomic per cent excess in workers and larvae after a pulse of ${ }^{13} \mathrm{C}$ and ${ }^{15} \mathrm{~N}$ isotopes. Workers became highly enriched rapidly (they collect the material) and then food was transferred to larvae by $96 \mathrm{~h}$. While not statistically significant, the atomic enrichment of ${ }^{13} \mathrm{C}$ trends toward being higher in larvae at $96 \mathrm{~h}$ while there is no pattern of difference in ${ }^{15} \mathrm{~N}$; this is opposite what was predicted. This assay was carried out with a single diet (ML, Medium-Low) in a subset of Lasius neoniger colonies. Variation is expressed as confidence intervals.

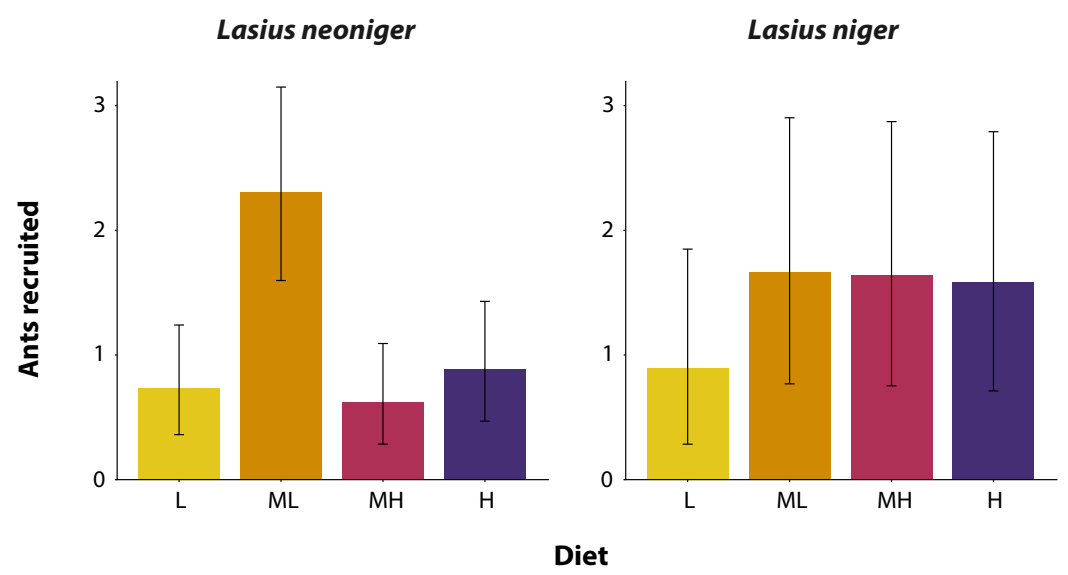

Fig 8. Field colonies of both Lasius species tended to avoid the diet with the highest protein content, and L. neonigerexhibited an overwhelming preference towards MH diet. L: Low carbohydrate content; ML: Medium-Low; MH: Medium-High; and H: High. Means and confidence intervals were extracted from the mixed-effects model using the effects library (Fox et al., 2018) and back-transformed. 

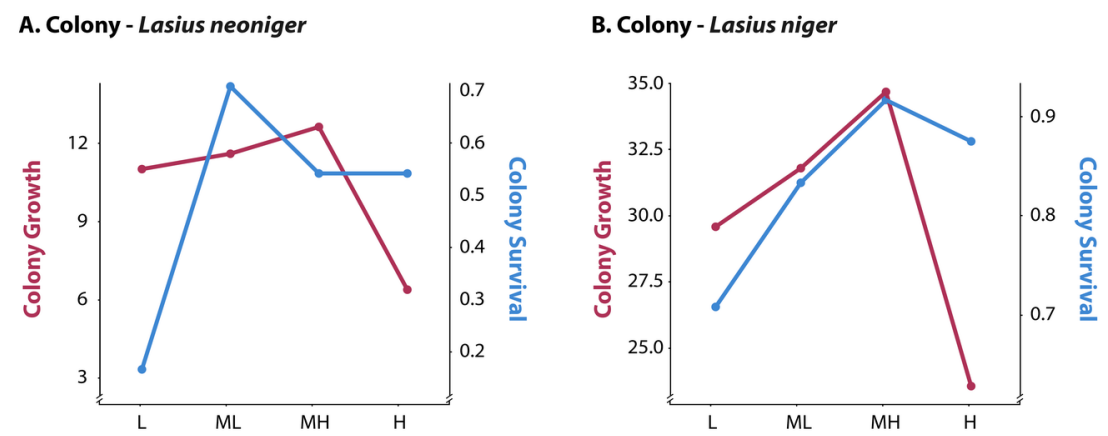

\section{Individual - Lasius neoniger}

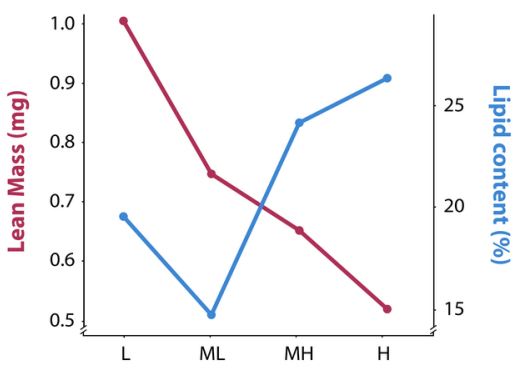

D. Individual - Lasius niger

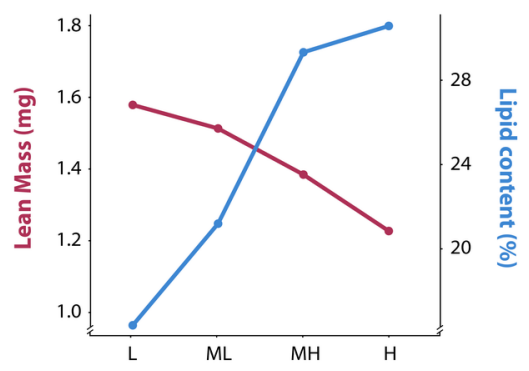

Fig 9. Untransformed values of colony survival and growth (A and B) and individual worker lean mass and lipid content (C and D). The lines intersect in all graphs, suggesting that both colony level growth and survival, as well as individual level lean and lipid mass, trade-off as a function of the carbohydrate and protein content in the diet (x-axis). In all cases, the lines intersect at the intermediate level (ML or MH) of $\mathrm{P}: \mathrm{C}$ used in this experiment.

\section{Supplementary Electronic Material}

Table S1. Recipes of diets used for the experiments

Table S2. Mixed-effect models results for colony development

Table S3. Two-way ANOVA results for overall colony growth

Table S4. Linear and generalized linear models results for workers phenotypes

Figure S1. Diet preference (i.e. recruitment) in field and laboratory colonies of Lasius neoniger 